\title{
Enhanced High-Temperature YSZ-polyester Abradable Honeycomb Seal Structures
}

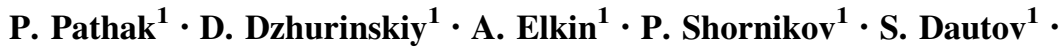 \\ V. Ivanov ${ }^{2}$
}

Submitted: 16 August 2021 / in revised form: 12 November 2021/ Accepted: 19 November 2021/Published online: 28 January 2022 (C) ASM International 2021

\begin{abstract}
The abradable coatings had significantly enhanced turbomachinery performance by acting as a sacrificial seal between rotating blades and stationary casing. Further improvement in seal design to meet the higher energy demand and increase the service time has been the key challenge to solve in the gas turbine industry. Honeycomb seals have become the industry standard clearance seal technique due to their unique design and high structural strength with minimum weight. The present study proposes a concept to form a thermal shock resistance structure to achieve higher temperature capability and improve the reliability of high-temperature abradable seal structures for a hot gas path of turbines. A cavity layer of honeycomb seal structure made of SS 321 alloy was coated with advanced high-temperature $\mathrm{ZrO}_{2}+7.5 \% \mathrm{Y}_{2} \mathrm{O}_{3}+4 \%$ polyester seal material using TriplexPro-210 plasma spray system. The integrity of a seal structure was assessed by a cross-sectional analysis and evaluation of the coating microstructure. Additionally, the micro-hardness test was performed to estimate coating fracture toughness, and finite element analysis was used to assess its thermo-mechanical
\end{abstract}

This article is an invited paper selected from presentations at the 2021 International Thermal Spray Conference, ITSC2021, that was held virtually May 25-28, 2021 due to travel restrictions related to the coronavirus (COVID-19) pandemic. It has been expanded from the original presentation.

\section{P. Pathak}

puskar.pathak@skoltech.ru

1 Center for Design, Manufacturing, and Materials, Skolkovo Institute of Science and Technology, Moscow, Russian Federation 143025

2 Honeycomb Department, Rotec JSC Company, Moscow, Russian Federation performance. The concept proposed in this study should be further validated to develop the most capable innovative technology for advanced gas turbine abradable seal structures.

Keywords abradable coating · APS · finite element analysis · gas Turbines · honeycomb Seal · YSZ

\section{Introduction}

The need to increase the efficiency of a modern gas turbine has always been demanding, and profound research work has been done in the past to achieve the goal. Among different adopted techniques, reducing the clearance between rotating blades and stationary casing in the highpressure section of the turbine was the key focus to minimize the gas leakage and enhance overall efficiency (Ref 13 ). The abradable coating had become an industry-standard method to reduce the clearance by acting as a sacrificial seal. In order to prevent the abrasive wear and frictioninduced overheating of dynamic components, the abradable counterpart coating should be softer and must within stand high temperature and oxidation resistance (Ref 4,5$)$. This design tailored thermal spray coatings applied to the housing's interior surface is characterized by their ability to withstand high temperature, provide a low thermal conductivity and erosion resistance, and ability to wear upon contact with turbine blade tips. The abradable seal coatings produced by the thermal spray coating technique are particularly advantageous because of their ability to form highly porous layers with tailored coating properties (Ref $6,7)$. The porosity within the coating varies from $35-60$ volume percent depending on the coating abradability requirement by controlling the amount of polyester within 
the coating (Ref 5). The abradable coatings are suitable for high-temperature turbines, which range from low-temperature, up to $450{ }^{\circ} \mathrm{C}$ (AlSi-based materials with graphite or polyester), medium-temperature $450-750{ }^{\circ} \mathrm{C}$ (MeCrAlYbased with boron nitride and polyester additions) and hightemperature (up to $1100{ }^{\circ} \mathrm{C}$ ) (Yttrium or Dysprosium stabilized Zirconia with polyester (Ref 5). These coatings have been primarily used in aviation gas turbines since the 1970s; however, due to the increase in fuel process, to enhance the turbine's efficiency and meet the high-energy demand, they are gaining popularity in land-based gas turbines and the power generation industry (Ref 8,9$)$.

Among the various forms of abradable seal used, honeycomb structures possess unique structure properties ensuring minimum gap and heat transfer rate into the parts with high structural strength to weight ratio when used as labyrinth seal (Ref 10,11). This is due to the flow accumulation within the small honeycomb cells, which preserve the gas flow movement. The hexagonal core cell structure provides excellent sealing by reducing hot gas leakage through the rotating blades and stationary casing of the hot section of the turbine. The honeycomb seal is mainly used for low and medium-temperature applications depending on the material used. The abradable honeycomb seals can withstand high-temperature oxidation, increase the radial expansion of rotor blades, and reduce cold build clearances, which improves the efficiency of gas turbines (Ref $12,13)$. These seals were proven to reduce leakage by up to $24 \%$ compared to the labyrinth seal and improve rotor stability (Ref 14).

Sporer et al. proposed an alternative approach of coating abradable materials in the structured surface to meet cyclic thermal resistance (Ref 15). The thermally sprayed abradable ceramics on the structured surface have advantages of dense coating thickness, rub inclusion, better coating adhesion, and thermal shock resistance. The thick-deposited zirconia-based ceramic materials on the brazed hexagonal honeycomb seal structure cells act as thermal insulation. These coatings can also find their usage for untipped blade abradability. The thermal sprayed abradable coating on the structured honeycomb seal could provide thermal isolation layers, which promote cyclic thermal stability. Besides the mentioned benefits of abradable coated honeycomb seal, little work has been published to understand the coating performance and its significance.

This work aims to study the proposed concept of creating a thermal shock resistance structure and discuss the improvement of abradable honeycomb seal structure design. The seal structure consists of metal honeycomb and ceramic material, $\mathrm{ZrO}_{2}+7.5 \% \mathrm{Y}_{2} \mathrm{O}_{3}+4 \%$ polyester. TriplexPro-210 plasma gun was used to coat the honeycomb seal structure with abradable ceramic material $\mathrm{ZrO}_{2}$ $+7.5 \% \mathrm{Y}_{2} \mathrm{O}_{3}+4 \%$ polyester. Atmospheric Plasma abradable coating offers extended temperature operating capability and greater spray process control to achieve the required coating morphology. The studied honeycomb seal structures are made of SS 321 alloy, and Rotec JSC provided complete assemblies. These high-quality welded honeycomb seals have been used in various aviation turbo engines, gas, and steam turbines (Ref 16). Coating microstructure features were investigated, and coating fracture toughness was estimated using a micro-hardness test. In addition, finite element analysis (FEA) was utilized to estimate thermal and structural behavior. Two numerical models were built using ABAQUS software. An apple-toapple comparison was conducted for the honeycomb and conventional ceramic abradable seal structure designs.

\section{Experimental Procedures}

\section{Materials}

The brazed honeycomb seal test specimens were produced by Rotec JSC, Russia, and used as substrate material. The substrate materials were grit-blasted using F24 alumina (grit size of $70 \mu \mathrm{m}$ ) and a standoff distance of $300 \mathrm{~mm}$. The commercially available agglomerated Metco 2460 NS $\left(\mathrm{ZrO}_{2}+7.5 \% \mathrm{Y}_{2} \mathrm{O}_{3}+4 \%\right.$ polyester $)$ abradable powder material was used. As reported, Metco 2460 NS possesses a higher porosity coating, which improves thermal shock life and abradability (Ref 17).

\section{Process Parameters and Coating Characterization}

The conventional atmospheric plasma spray (APS) process with TriplexPro-210 spray gun was used to deposit yttriastabilized zirconia (YSZ) abradable material spraying process parameters used are summarized in Table 1. The temperature of the coated specimen was monitored

Table 1 Atmospheric plasma spray coating parameters

\begin{tabular}{ll}
\hline Process APS parameters & \\
\hline Primary plasma gas (Ar), NLPM & 60 \\
Secondary plasma gas ( $\mathrm{N}_{2}$ ), NLPM & 4 \\
Electric Power, kW & 25.2 \\
Powder carrier gas (Ar), NLPM & 3.5 \\
Nozzle diameter, mm & 9 \\
Powder injector diameter, mm & 1.8 \\
Powder feeding rate, $\mathrm{g} / \mathrm{min}$ & 31 \\
Standoff distance, mm & 120 \\
TriplexPro-210 travel speed, $\mathrm{mm} \cdot \mathrm{s}^{-1}$ & 1000 \\
\hline
\end{tabular}


regularly using an infrared thermometer after deposition to control substrate overheating. The average arithmetical surface roughness was measured using Surtronic S100 roughness tester and reported at $7 \mu \mathrm{m}$. The standard coating metallography preparation guide for soft abradable materials was followed to prepare mounted samples. The integrity of the coating microstructure was assessed by an optical microscope Carl Zeiss Axio Scope A1 and followed by the image analysis using ThixometPro software.

Fracture toughness $(\mathrm{Kc})$ as a measure of a material's resistance to extension under predominantly linear-elastic conditions was calculated by Evans and Wilshaw (Eq 1) (Ref 18). A Vickers microhardness test was performed to estimate coating fracture toughness using the METROTEST hardness tester, while the coating crack propagation was assessed, and the results were compared against honeycomb and the conventional structure.

$K c=0.079 \cdot\left(\frac{P}{a^{\frac{3}{2}}}\right) \log \left(\frac{4.5 a}{c}\right)$

\section{Finite Element Analysis}

The thermo-mechanical behavior was numerically investigated by performing FEA implemented in Abaqus/Standard CAE. If deformations caused by thermal expansion do not affect the temperature distribution, a sequentially coupled thermal-stress analysis procedure was used. The temperature distribution was determined using a heattransfer solver, and that temperature field was applied as a resulting thermal loading condition to calculate the level of generated thermal stress. Obtained results of stress distribution were compared for two configuration cases: honeycomb structure and conventional substrate designs, where the coating is evenly distributed over the substrate. The stress analysis consists of the heating cycle (from $20{ }^{\circ} \mathrm{C}$ up to $1200{ }^{\circ} \mathrm{C}$ ) and the cooling cycle (cooling down back to $20^{\circ} \mathrm{C}$ ) to estimate thermal and residual stresses. Temperatures were chosen by estimating the hot gas path conditions of a turbine.

The model of honeycomb structure design is presented in Fig. 1, and dimensions are shown in Table 2. The green color represents YSZ ceramic material used as a coating layer, and the substrate AISI 321 is shown in grey. In the model, it is assumed that FEA elements have common nodes, and there are no gaps or voids present between the honeycomb structure and YSZ coating layer.

The hexagonal C3D8R elements were used, and the model was discretized using $0.06 \mathrm{~mm}$ mesh. Additionally, the mesh sensitivity study was conducted to accomplish a residual error of less than $5 \%$.
A nonlinear plastic model with temperature-dependent properties for AISI 321 substrate material was used to predict thermo-mechanical behavior (Ref 19). The properties of porous yttria-stabilized zirconia coating are considered temperature independent in this study (Ref 20 due to negligible property changes in the chosen temperature range. The properties are summarized in Table 3.

The heat transfer analysis was conducted using boundary conditions as depicted in Fig, 2(a) and then thermomechanical analysis to assess the stresses due to temperature distribution. Mechanical constraints consist of force distribution element RBE-3 connected between fixed node and bottom substrate surface. The lateral sides along $\mathrm{X}$ are constrained. The mechanical boundary conditions are presented in Fig. 2(b).

\section{Results and Discussion}

\section{Microstructural and Mechanical Characterizations}

Figure 3 shows the microstructure of Metco 2460NS coating layers deposited using TriplexPro-210 to honeycomb and conventional substrate designs.

The image analysis of deposited coating layer microstructure shows approximately 56 and $45 \%$ of porosity content in deposited coating layers, where $4 \%$ of polyester addition is responsible for increasing a level of coating porosity. The higher porosity level in the honeycomb substrate could contribute to a better abradability during turbine blade incursion by reducing the hardness, erosion resistance, and cohesive strength of the coating. This could play a significant role in decreasing the microrupture force due to pulling particles out of the coating layer and therefore increasing the effect of seal' abradability. The honeycomb structure also provides the mechanical anchoring for a coating layer where the cell acts as a strain isolator - this is a unique feature to facilitate a thermal shock resistance of the applied coating (Ref 15). The shading effects from the thermal spray mass flux resulting from gas vortices generation were also observed to play a critical role in developing coating layer defects near the rib (Fig. 3a), suggesting optimization in honeycomb cell design. Moreover, the shading effect affects the heat distribution and level of residual stresses while there is a need to perform thermal cycling and abradability tests to estimate durability of coating layers under operational conditions.

The fracture toughness of deposited coatings was analyzed using the Evans and Wilshaw equation (indentation method) while measurements were taken at 500, 750, and 1000 gf, respectively, and the Kc values were calculated 


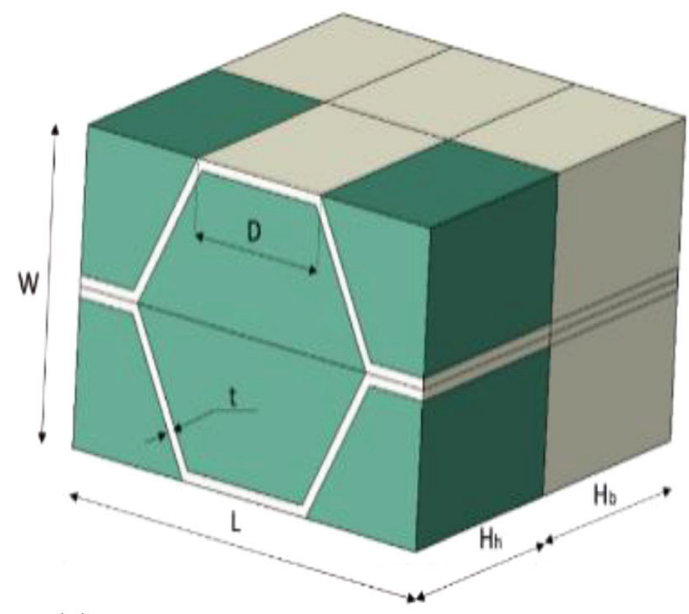

(a)

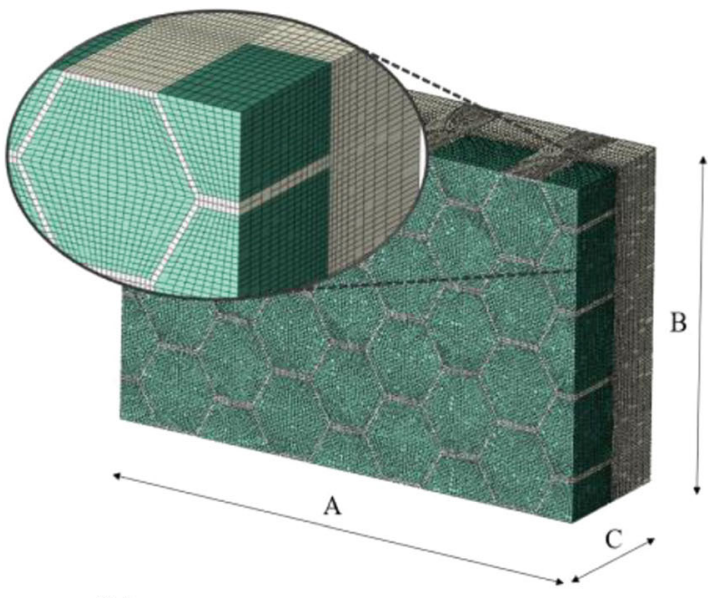

(b)

Fig. 1 Honeycomb dimensions and structure design representation: (a) dimensions of the honeycomb cell; (b) an overall model view

Table 2 Dimensions of the honeycomb structure

Honeycomb structure $(\mathrm{mm})$

$\mathrm{D}$, length of a honeycombed side

0.9

$\mathrm{W}$, cell width

1.67

L, cell length

$\mathrm{t}$, honeycomb web thickness

$\mathrm{H}_{\mathrm{h}}$, height of the honeycomb

$\mathrm{H}_{\mathrm{b}}$, thickness of the base

Overall model dimensions ( $\mathrm{mm}$ )
A, Length
B, Width
C, Thickness
10.8
6.7
3

2.7

0.06

1.5

1.5

Table 3: Material properties of yttria-stabilized zirconia

Yttria-Stabilized Zirconia

\begin{tabular}{ll}
\hline Elasticity, GPa & 210 \\
Poisson's Ratio & 0.3 \\
$\mathrm{CTE}, \mu \mathrm{m} / \mathrm{m}^{\circ} \mathrm{C}$ & 10 \\
Thermal Conductivity, $\mathrm{W} / \mathrm{m}^{\circ} \mathrm{Cc}$ & $0.3($ Ref 21,22$)$ \\
Flexural strength, $\mathrm{MPa}$ & 950 \\
\hline
\end{tabular}

using Eq 1. Figure 4 shows an indentation mark with the measures to calculate fracture toughness value.

Due to a coating microstructure complexity (high level of porosity), 15 indentations were used to estimate the value of fracture toughness. The resulting average fracture toughness values are presented in Fig. 5 for coating with the conventional substrate and honeycomb structure designs.
Kc value increased with indentation load in a conventional substrate with a maximum fracture toughness value of $2.5 \mathrm{MPa} \cdot \mathrm{m}^{1 / 2}$ revealed at $1 \mathrm{~kg}$, whereas for honeycomb, the values stay at about $2.0 \mathrm{MPa} \cdot \mathrm{m}^{1 / 2}$. The significant deviation in $\mathrm{Kc}$ values is attributed to the irregularity of coating microstructure possessing high-level porosity. Moreover, it was established that the lower fracture toughness is attributed to the coating of higher porosity and is associated with a lower strength of cohesive coating energy (Fig. 5) while providing a decrease in the coating micro-rupture, similar to previously reported findings (Ref 23).

\section{Simulation Results}

Physical properties of both substrate and powder feedstock used for the coating deposition strongly influence the resulting stress state. In this study, an attempt to compare two abradable seal designs was made. With this regard, a thermo-mechanical analysis was conducted using finite element analysis. The calculated temperature distribution is shown in Fig. 6. The stress analysis results are depicted in the form of a two-dimensional map of principal stresses (Fig. 7) and a distribution of principal stresses along the $\mathrm{Z}$ mid-thickness line (Fig. 8).

The calculated stresses in the YSZ coating are negligible (below $10 \mathrm{MPa}$ ). High compression is observed in the substrate during heating and significant tensile residual stresses after cooling (Fig. 7). Compared to the conventional substrate, the honeycomb substrate design shows a $10 \%$ lower principal stress value in the interphase region between substrate and coating (Fig. 8). However, near the bottom surface, the obtained stresses are slightly higher.

The maximum principal compressive stress of -116 MPa was observed for conventional substrate, whereas the 
Fig. 2 Boundary conditions used in FEA analysis:

(a) thermal loading; (b) model constraints for stress analysis

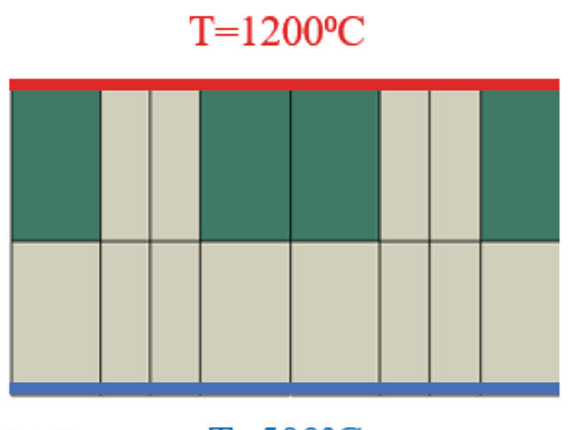

$\underset{z}{\longmapsto} \times \quad T=500^{\circ} \mathrm{C}$

(a)
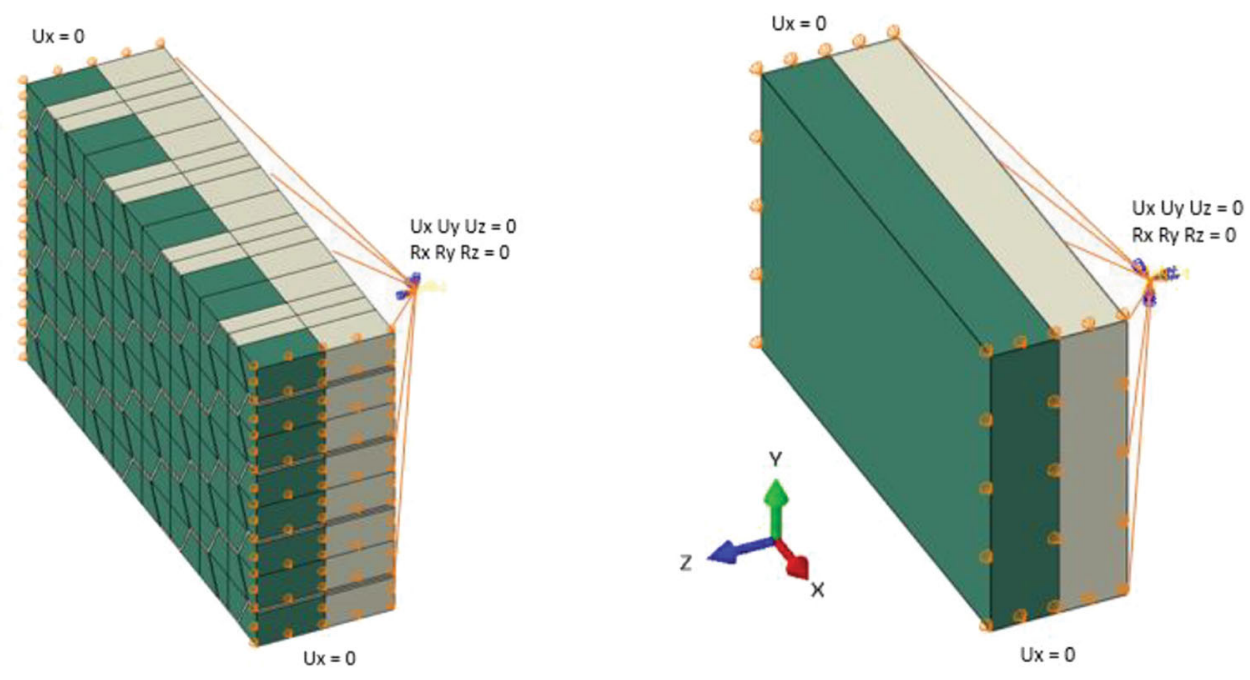

(b)

Fig. 3 Microstructure of Metco 2460NS coating layer deposited by APS to the substrate materials: (a) honeycomb substrate; (b) conventional substrate
$\mathrm{T}=1200^{\circ} \mathrm{C}$

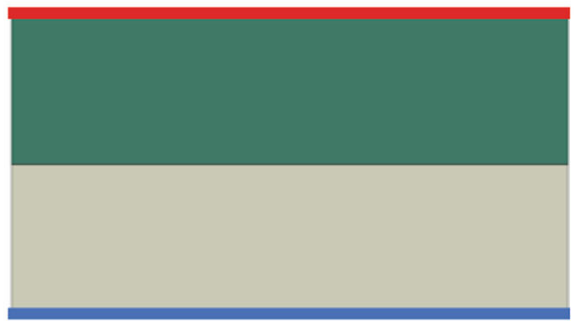

$\underset{z}{y x} \quad \mathrm{~T}=500^{\circ} \mathrm{C}$

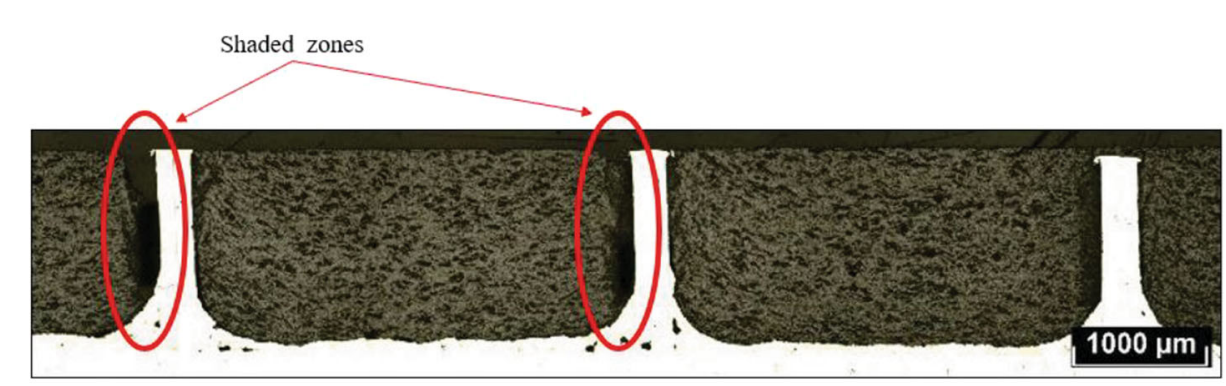

(a)

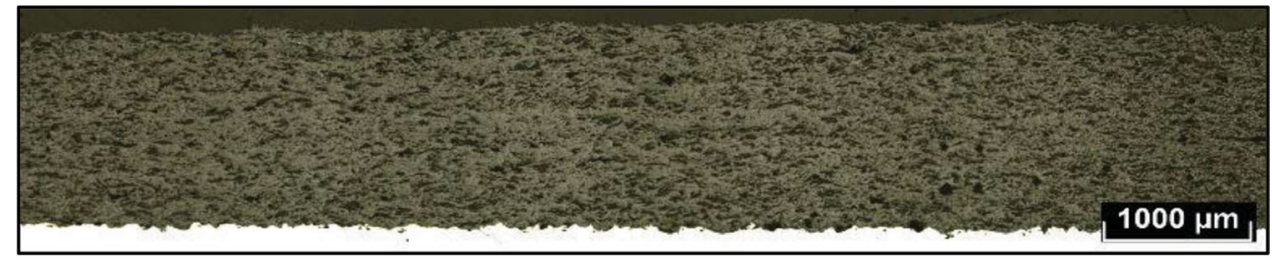

(b) 


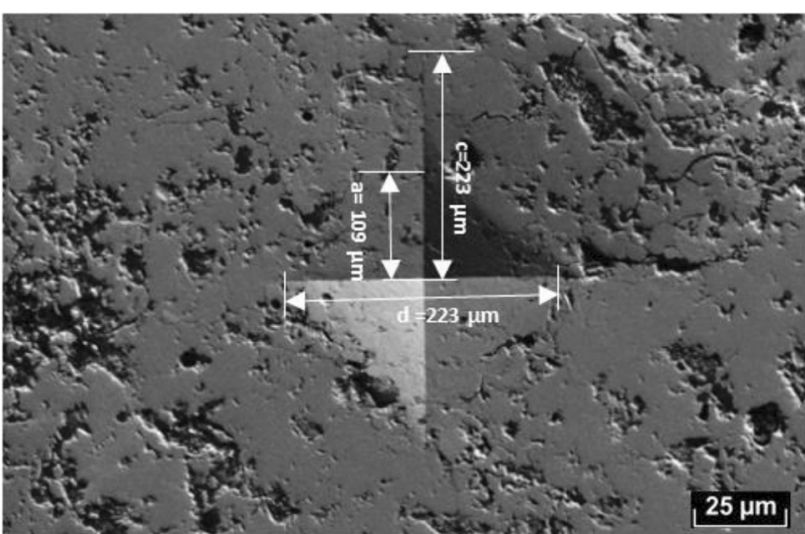

Fig. 4 SEM image of Vickers indent at $1 \mathrm{kgf}$ load into Metco 2460NS coating layer. (a) Half of the diagonal indent length, (c) crack length from the indented center, (d) total diagonal length

- Honeycomb substrate Conventional substrate

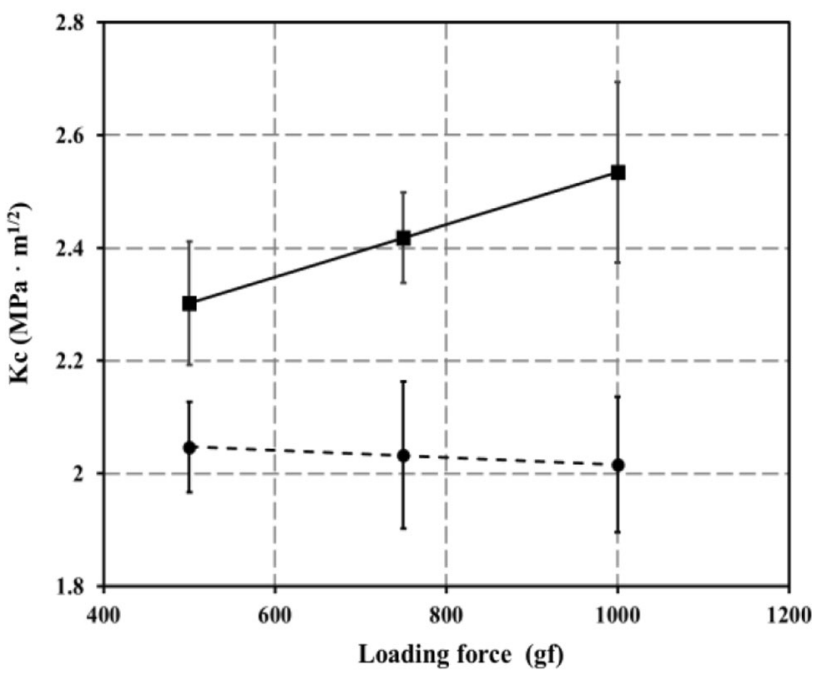

Fig. 5 Fracture toughness of deposited Metco 2460NS coating layers

stresses in the honeycomb substrate stabilized at -117 MPa. The highest principal tensile stress of $278 \mathrm{MPa}$ was found in the substrate within with honeycomb design, which is $6.5 \%$ higher than in the case of conventional design. Nevertheless, results near the interphase region are in favor of the honeycomb substrate design. At the interphase ( $\mathrm{Z}$ mid thickness line $1.5 \mathrm{~mm}$ ), the maximum principal tensile stresses in the honeycomb substrate are 232 MPa. That is $12 \%$ lower than in the conventional substrate. The maximum principal compressive stresses of $107 \mathrm{MPa}$ are $8.5 \%$ lower for honeycomb substrate. The stress results indicate negligibly small thermal stresses in the porous YSZ coating due to low CTE. This means that stresses at the interphase are a critical factor causing coating delamination. Honeycomb substrate filled with YSZ showed lower interphase stresses compared with the conventional

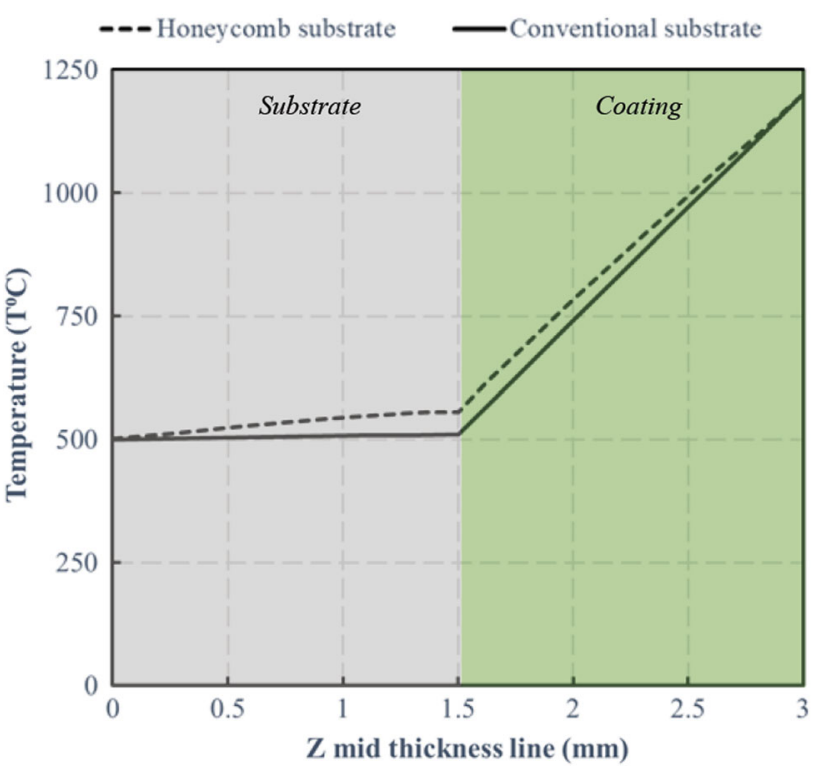

Fig. 6 The calculated temperature distribution in the honeycomb and conventional structures.

structure so that it may have less tendency to delamination, similar to previously reported data (Ref 24). Further development of FEA model requires considering the shading effect, which was experimentally observed. This involves a mesh modification approach where a gap between YSZ coating and honeycomb wall is introduced. Moreover, consideration of a cohesive zone model (CZM) implementation to simulate the interaction between honeycomb substrate and YSZ coating could reveal delamination during the modeling of thermal cyclic behavior.

\section{Conclusions}

This study demonstrates the applicability of forming the thick and porous YSZ coatings on honeycomb steel structures utilized APS. YSZ filled honeycomb design might improve the structural integrity of the abradable honeycomb seal structures. Microstructural analysis revealed shadow zone defects occur under certain spraying parameters. The experimental results also reveal improvement in coating' fracture toughness of the honeycomb structure in comparison to conventional APS coatings. FEA analysis results showed fewer stresses at the interphase, suggesting a potential enhancement of abradable seals design to withstand higher thermal load conditions without delamination. Furthermore, there is a need to perform thermal cycling tests to estimate the durability of coating layers.

Moreover, this study revealed a need for further enhancement of honeycomb cell design and spraying 

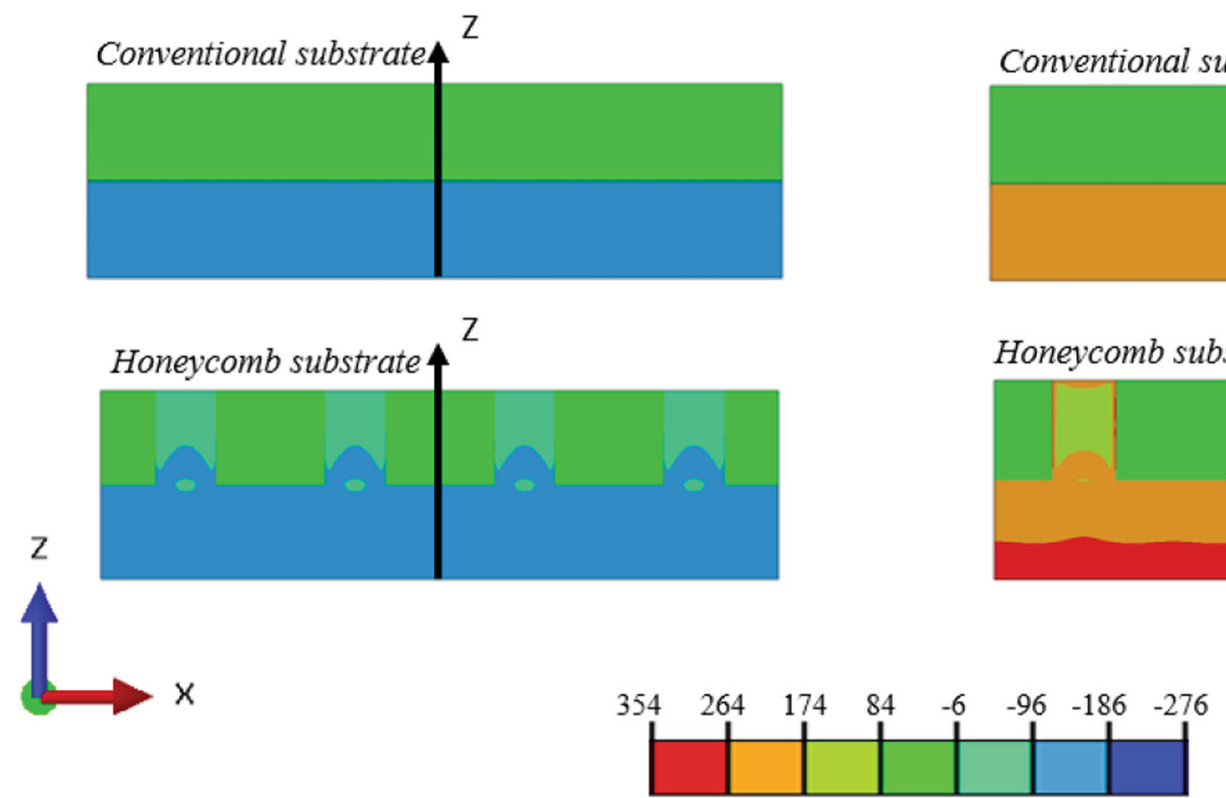

Absolute principal stress $(\mathrm{MPa})$
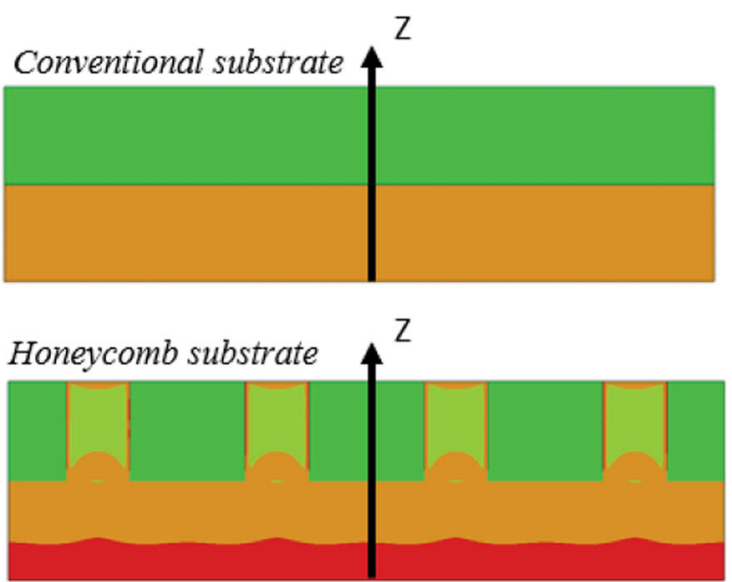

(b) Cooling cycle

Fig. 7 Two-dimensional map of the thermal stress distribution: (a) Heating cycle (b) Cooling cycle

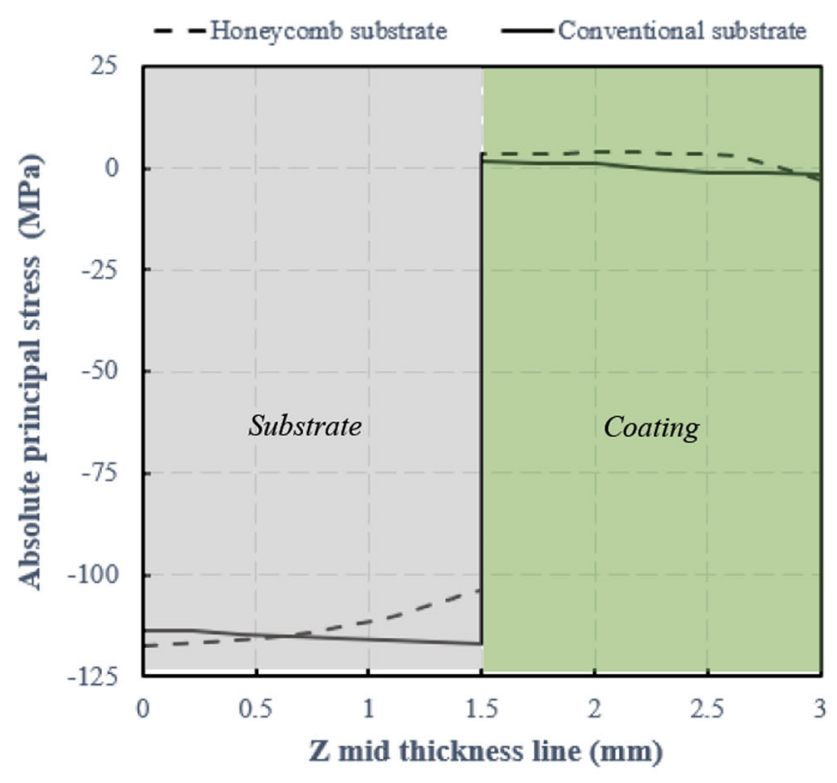

(a) Heating cycle

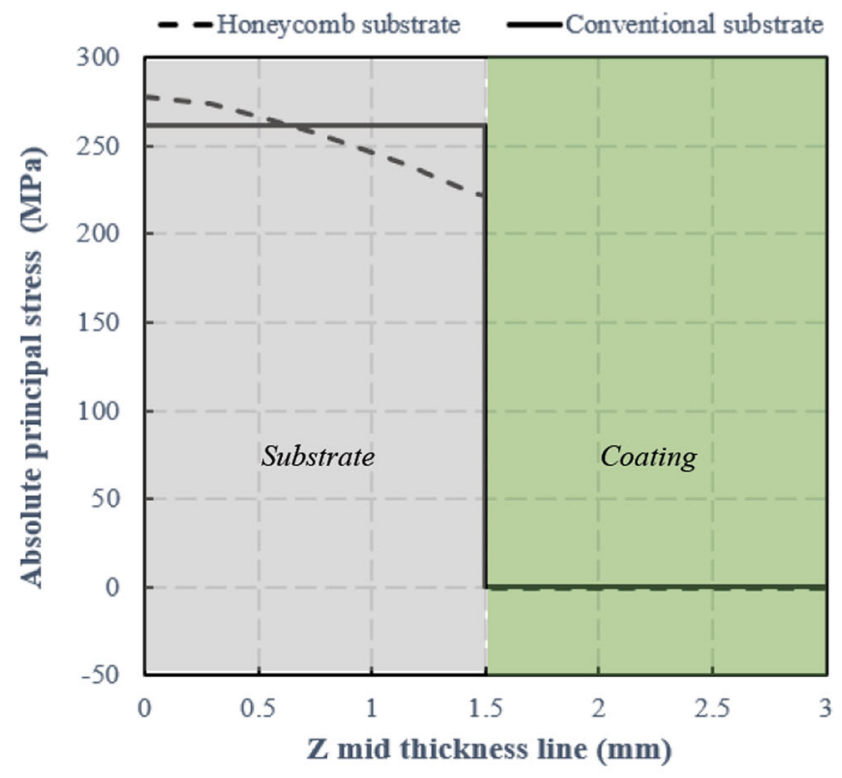

(b) Cooling cycle

Fig. 8 Distribution of principal stress along Z mid-thickness line (see Fig. 7): (a) Heating cycle (b) Cooling cycle

parameters adjustment to decrease shadow effects during spraying operation, therefore improving the coating integrity of the abradable seal structure.
Acknowledgments The authors want to acknowledge Rotec JSC Company, https://zaorotec.com, for providing assembled honeycomb panels. 


\section{References}

1. D. Sporer, S. Wilson, P. Leader, M. Giannozzi, On the potential of metal and ceramic based abradables in turbine seal applications, in Proceedings of the thirty-sixth Turbomach. symptoms, 2007, p 79-86.

2. X. Sun, Z. Liu, L. Du, H. Lan, H. Zhang, C. Huang, M. Xiang, W. Zhang, A Study on YSZ Abradable Seal Coatings Prepared by Atmospheric Plasma Spray and Mixed Solution Precursor Plasma Spray, Journal of Thermal Spray Technology. 2021.

3. D. Tejero-Martin, M. Rezvani-Rad, A. McDonald and T. Hussain, Beyond Traditional Coatings: A Review on ThermalSprayed Functional and Smart Coatings, Journal of Thermal Spray Technology, 2019 https://doi.org/10.1007/s11666-01900857-1

4. D. Sporer, S. Wilson, P. Fiala, R. Schuelein, Thermally sprayed abradable coatings in steam turbines: design integration and functionality testing, paper no. GT2010-23568, Power for Land, 2010, p 2309-2317 http://www.asme.org/about-asme/terms-ofuse.

5. S. Wilson, Thermally Sprayed Abradable Coating Technology for Sealing in Gas Turbines, in 6th International Gas Turbine Conference the Future of Gas Turbine Technology, 2012, p 1-9.

6. T. Steinke, G. Mauer, R. Vaßen, D. Stöver and D. Roth-Fagaraseanu, Process Design and Monitoring for Plasma Sprayed Abradable Coatings, J. Therm. Spray Technol., 2010, 19(4), p 756-764.

7. N.P. Hopkins, Abradable Coatings - From Black Art, To Materials Science, 2007, p 1-209.

8. R.E. Chupp, Y.-C. Lau, F. Ghasripoor, D.J. Baldwin, Development of higher temperature abradable seals for gas turbine applications, paper no. GT2004-53029, Power for Land, 2004, http://www.asme.org/about-asme/terms-of-use.

9. C.U. Hardwicke and Y.C. Lau, Advances in Thermal Spray Coatings for Gas Turbines and Energy Generation: A Review, Journal of Thermal Spray Technology, 2013, 22, p 564-576.

10. T.W. Ha and D.W. Childs, Annular Honeycomb-Stator Turbulent Gas Seal Analysis Using a New Friction-Factor Model Based on Flat Plate Tests, J. Tribol., 1994, 116(2), p 352-359.

11. R. Benoit, E. Beverly, C. Love, Honeycomb Abradable Seals, US Patent WO 1995021319A1 1995.

12. D.J. Potter, Y.W. Chai and G.J. Tatlock, Improvements in Honeycomb Abradable Seals, Mater. High Temp., 2009, 26(2), p 127-135.
13. P.C. Collins, J. Teixeira and P. Crudgington, The Degradation of Abradable Honeycomb Labyrinth Seal Performance Due to Wear, Seal. Technol., 2008, 2008(8), p 7-10.

14. H.L. Stocker, D.M. Cox, G.F. Holle, Aerodynamic performance of conventional and advanced design labyrinth seals with solidsmooth abradable, and honeycomb land, NASA Technical Report, 1977.

15. H. Brodin, Thermomechanical fatigue life of TBCS - experimental and modeling aspects, Advanced Ceramic Coatings and Interfaces V, 2010 The American Ceramic Society, 2010, p 23-39

16. "Honeycomb Seals ROTEC JSK Is the First Company in Russia Specialized in Manufacturing Honeycomb Seals for Turbines," n.d., https://zaorotec.com/honeycomb-materials/. Accessed 5 November 2021.

17. DSMTS-0014.4-Zirconium Oxide Ceramic Abradable Powders, 2017.

18. A.G. Evans and T.R. Wilshaw, Quasi-Static Solid Particle Damage in Brittle Solids-I Observations Analysis and Implications, Acta Metall., 1976, 24(10), p 939-956.

19. “Alloy 321 - Premium Stainless Steel Grades," n.d., https://www. neonickel.com/alloys/stainless-steels/alloy-321. Accessed 5 November 2021.

20. "Yttria Stabilized Zirconia (YTZP). Superior Technical Ceramics," n.d., https://www.ceramics.net/ceramic-materials-solutions/ zirconias/ytzp. Accessed 5 November 2021.

21. L. Hu, C.A. Wang, Z. Hu, S. Lu, C. Sun and Y. Huang, Porous Yttria-Stabilized Zirconia Ceramics with Ultra-Low Thermal Conductivity. Part II: Temperature Dependence of Thermophysical Properties, J. Mater. Sci., 2011, 46(3), p 623-628.

22. W. Peiman, I. Pioro and K. Gabriel, Thermal Design Aspects of High-Efficiency Channel for Supercritical Water-Cooled Reactors (SCWRs), Nucl. Eng. Des., 2013, 264, p 238-245. https://doi. org/10.1016/j.nucengdes.2013.02.021

23. A. Paraschiv, G. Matache, C. Puscasu, M. Grigorescu, A Correlation Between Fracture Toughness and Cohesion Strength of Molybdenum Thermal Sprayed Coatings, MATEC Web Conference, 2018, 145.

24. A.A. Abubakar, A.F.M. Arif and S.S. Akhtar, Evolution of Internal Cracks and Residual Stress during Deposition of TBC, Ceram. Int., 2020, 46(17), p 26731-26753. https://doi.org/10. 1016/j.ceramint.2020.07.148

Publisher's Note Springer Nature remains neutral with regard to jurisdictional claims in published maps and institutional affiliations. 